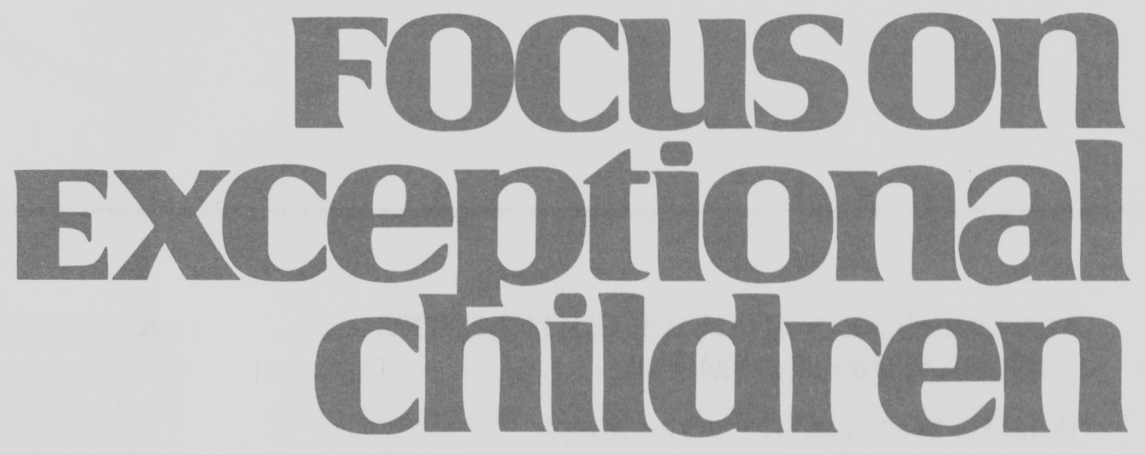

\title{
Co-Teaching: Guidelines for Creating Effective Practices
}

\author{
Lynne Cook, Ph.D., and Marilyn Friend, Ph.D.
}

Although the isolation of the teaching profession long has been recognized and has often been commented upon (Barth, 1990; Lortie, 1975), for the past three decades educators also have been intrigued with the possibilities created by two teachers' sharing one classroom. As early as the 1960s (e.g., Trump, 1966), co-teaching was recommended as a strategy for reorganizing secondary schools in the United States as well as in England (Warwick, 1971). A variation of co-teaching - team teaching, in which teachers share planning responsibilities for instruction while they continue to teach separately - was adopted in many openconcept schools during the 1970s (Easterby-Smith \& Olive, 1984). More recently, renewed interest in co-teaching has emerged as part of the middle school movement and other school reform efforts (MacIver, 1990).

As a service delivery option in special education, pairs of special educators used coteaching to share their responsibilities for students in self-contained classrooms (Garvar \& Papania, 1982). Further, co-teaching grew rapidly in response to factors recognized during the early days of mainstreaming, including the need for special education teachers and general education teachers to work in constructive and coordinated ways (Bauer, 1974; Walker, 1974) and increasing expectations that students with disabilities be educated in classrooms with their nondisabled peers. By the late 1980s, co-teaching was discussed most often as a means for special education teachers to meet students' needs in general education settings.

Much of the current literature on co-teaching as it relates to special education consists of educators' detailed anecdotal accounts of successful co-teaching programs and experiences (e.g., Adams \& Cessna, 1991; Howell, 1991; White \& White, 1992). Others have raised questions or dedicated entire articles or chapters to discussions of the limitations of and problems with co-teaching and its collaborative elements (e.g., Fuchs \& Fuchs, 1992; Pugach \& Johnson, 1995; Reeve \& Hallahan, 1994). In the meantime, schools planning to include co-teaching as part of their inclusive practices are asking how to go about setting up co-teaching programs that are both responsive to the needs of students as well as feasible in the eyes of teachers.

The purpose of this article is to raise and discuss many of the issues and concerns that can guide the thinking and practice of professionals as they strive to design and implement responsible co-teaching programs. Our intent is not so much to provide a single set of "right" answers as to try to ensure that the questions have been asked so that professionals planning to co-teach can make deliberate and reflective choices concerning this service delivery option.

Dr. Cook is a professor of education at California State University, Northridge, and Dr. Friend is an associate professor of education at Indiana University-Purdue University at Indianapolis. 


\title{
TEN QUESTIONS TO GUIDE CO-TEACHING PROGRAM DEVELOPMENT
}

\section{What Do We Mean by Co-Teaching?}

When teachers discuss co-teaching, a similar understanding of the co-teaching concept is important. Our definition is as follows:

\begin{abstract}
two or more professionals delivering substantive instruction to a diverse, or blended, group of students in a single physical space.
\end{abstract}

This definition includes four key components which are elaborated here. First, co-teaching involves two educators*, and occasionally, more. For purposes of the discussion here, one of the professionals is a general education teacher and the other is a special educator - either a special education teacher or a specialist in one of the related services such as a

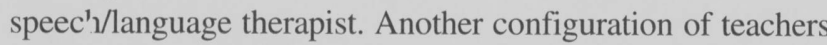
falling under the rubric of co-teaching may be two middle school teachers teaching English and social studies in an integrated block. The intent here, however, is to focus on the somewhat unique possibilities that occur from the different but complementary perspectives of the professionals involved: General educators who specialize in understanding, structuring, and

\section{FOCUSOn Exceptional children}

ISSN 0015-511X FOCUS ON EXCEPTIONAL CHILDREN (USPS 203-360) is published monthly except June, July, and August as a service to teachers, special educators, curriculum specialists, administrators, and those concerned with the special education of exceptional children. This publication is annotated and indexed by the ERIC Clearinghouse on Handicapped and Gifted Children for publication in the monthly Current Index to Journals in Education (CIJE) and the quarterly index, Exceptional Children Education Resources (ECER). The full text of Focus on Exceptional Children is also available in the electronic versions of the Education Index. It is also available in microfilm from Xerox University Microfilms, Ann Arbor, MI. Subscription rates: Individual, \$30 per year; institutions, $\$ 40$ per year. Copyright (C) 1995, Love Publishing Company. All rights reserved. Reproduction in whole or part without written permission is prohibited. Printed in the United States of America. Second class postage is paid at Denver, Colorado. POSTMASTER: Send address changes to:

$$
\begin{aligned}
& \text { Love Publishing Company } \\
& \text { Executive and Editorial Office } \\
& 1777 \text { South Bellaire Street } \\
& \text { Denver, Colorado } 80222 \\
& \text { Telephone (303) } 757-2579
\end{aligned}
$$

Edward L. Meyen University of Kansas

Richard J. Whelan

University of Kansas Medical Center
Stanley F. Love

Publisher
Glenn A. Vergason Georgia State University

Kristin Kennedy

Editorial Assistant pacing curriculum for groups of students are paired with special educators who specialize in identifying unique learning needs of individual students and enhancing curriculum and instruction to match these needs. Related services professionals also may be involved. This is elaborated further in the section, "Who Should Be Involved in Co-Teaching?" This linking of educational perspectives becomes a strategy for creating classroom communities in inclusive schools (Friend, Reising, \& Cook, 1993).

More than two educators can be present in the classroom. Moreover, in some co-taught classes, paraprofessionals, parent volunteers, or older student volunteers also have roles in assisting the teachers. But these arrangements do not meet the definition of co-teaching as we have articulated it.

The second part of our co-teaching definition specifies that the educators deliver substantive instruction. They do not supervise a study hall, support a single student, monitor students who are listening to a guest speaker, or assist in delivering instructional add-ons that are related only marginally to the curriculum of the general education classroom. This definitional component emphasizes that both professionals are involved actively in the instruction of students.

Third, the educators teach a diverse group of students, including students with disabilities. Co-teaching involving special educators or related services specialists is undertaken because students with individualized educational programs (IEPs) have educational needs that can be met by moving their supports to the general education classroom through this instructional arrangement.

Finally, in co-teaching the instruction is delivered primarily in a single classroom or physical space. This does not preclude

\section{*We use the terms educator, teacher, and professional throughout this article to designate professionally prepared and licensed teachers and related serv- ices providers.}

STATEMENT OF OWNERSHIP, MANAGEMENT, AND CIRCULATION

Date of Filing: October 18, 1995

Title of Publication: Focus on Exceptional Children

Frequency of Issue: Monthly (except June, July \& August)

Location of Known Office of Publication:1777 S. Bellaire Street, Denver, Colorado 80222-4306

Location of Headquarters of Publisher: 1777 S. Bellaire Street, Denver, Colorado 80222-4306

Name and Address of Publisher, Editor, and Managing Editor: Stanley F. Love, 1777 S. Bellaire Street, Denver, Colorado 80222-4306 Owner: Stanley F. Love

Extent and Nature of Circulation:

Total No. Copies Printed

Average No. Copies Each Issue During

Paid Circulation Preceding 12 Months

Sales through Dealers, etc. Mail Subscriptions

Total Paid Circulation

Free Distribution

Total Distribution

Office Use and Left Over

Total 2,335

$$
\begin{gathered}
\text { Single Issue } \\
\text { Nearest } \\
\text { Filing Date } \\
2,210
\end{gathered}
$$

$\begin{array}{rr}0 & 0 \\ 1,835 & 1,829 \\ 1,835 & 1,829 \\ 423 & 307 \\ 2,258 & 2,136 \\ 77 & 74 \\ 2,335 & 2,210\end{array}$

I certify that the statements made by me above are correct and complete. 
the possibility of occasionally separating groups of students for instruction that involves considerable activity with possible high levels of noise and distraction, but it does eliminate from consideration situations in which teachers coordinate instruction (for example, plan an integrated unit together) but deliver it to separate groups of students in separate locations. The latter is sometimes a recommended instructional practice and well may be an excellent example of collaborative planning, sometimes referred to as co-planning, but it does not involve the considerably more complex set of issues that arise when two teachers share instruction in one classroom.

\section{Variations in Practice}

Co-teaching is just one of several structures or arrangements used by professionals who collaborate in providing special education and related services to special needs students in general education classrooms. Ideally, co-teaching includes collaboration in all facets of the educational process. It encompasses collaboratively assessing student strengths and weaknesses, determining appropriate educational goals and outcome indicators, designing intervention strategies and planning for their implementation, evaluating student progress toward the established goals, and evaluating the effectiveness of the co-teaching process.

What is ideal and what is pragmatic, however, are often different. Variations in student needs, caseloads and class size, competing professional responsibilities, and scheduling are among the reasons that collaboration in the full range of activities that support co-teaching is not always possible. Although we encourage professionals to collaborate as fully as possible throughout their teaching and service delivery, we will limit our discussion of co-teaching here to the collaborative delivery of instruction.

\section{Further Sorting Vocabulary}

A deeper understanding of the meaning of co-teaching can be derived by distinguishing it from other activities on behalf of students as we have done above. For example, we agree with others who clarify that co-assessment (Choate, 1993), problem solving and intervention planning teams (Graden, 1989; Phillips \& McCullough, 1990; Pugach \& Johnson, 1989), consultation (Heron \& Harris, 1993), and individualized educational planning teams (Friend \& Cook, 1996) are distinct activities in which educators might participate collaboratively to enhance education and services. Co-teaching will benefit from educators' collaborative efforts in all of these and similar activities. Co-teaching, however, is uniquely different from these activities in that it is an approach for special educators and related services professionals to provide direct service to students with special needs during instruction within the general education classroom.
Collaborative problem-solving approaches and joint planning efforts, in contrast, are generally indirect services, as the special educators interact directly with the teachers, who then interact directly with the students. The special educator or related services provider serves the student indirectly in this fashion.

Finally, though co-teaching — as well as the other activities mentioned - contributes to inclusive practices, it is not synonymous with inclusion. Inclusion can be accomplished in many ways depending on the students' needs just as coteaching may be done to accomplish many goals other than inclusion. Yet co-teaching is clearly just one approach that is valuable for facilitating the inclusion of some students.

\section{What is the Rationale for Co-Teaching?}

Before deciding to begin a co-teaching program, professionals should have opportunities to clarify what they hope to accomplish by using this approach to meet student needs, particularly since it places new demands on the adults involved and requires them to reconsider their professional roles. The following are among the most salient elements of a rationale for co-teaching:

1. Increase instructional options for all students.

2. Improve program intensity and continuity.

3. Reduce stigma for students with special needs.

4. Increase support for teachers and related service specialists.

\section{Increasing Instructional Options}

Any discussion of reasons for co-teaching should begin with an understanding of the potential benefits to students. For example, co-teaching can be characterized as a means of bringing the strengths of two teachers with different expertise together in a manner that allows them to better meet student needs (Bauwens, Hourcade, \& Friend, 1989; Walsh, 1992). From this perspective, a primary rationale for co-teaching is that it increases opportunities for student success through expanding instructional approaches. Although research supporting the value of co-teaching is limited, some is beginning to emerge demonstrating greater academic gains for students when their teachers receive consultation and participate in coteaching (Schulte, Osborne, \& McKinney, 1990).

One way of understanding this part of a co-teaching rationale is to think of co-teaching as an opportunity to increase the instructional options for all students. For example, although co-teaching occurs because students with disabilities need support services in a general education classroom, gifted and talented students may also benefit because more options can be created for individualizing their learning. Likewise, students who struggle to learn but who are not eligible for special education or other support services gain the benefit of a reduced student-teacher ratio and the instructional variety that co-teaching brings. 


\section{Improving Program Intensity and Continuity}

A second reason for co-teaching concerns the intensity and integrity of students' educational programs. First, in cotaught classes, students can receive more instruction and are involved more systematically in their learning than would be possible in a classroom with only one teacher. Moreover, the combination of two teachers reduces the student-teacher ratio and provides opportunities for greater student participation and engaged time. Also, co-teaching enables students who otherwise might leave the classroom for their special education or related services to spend more time in one instructional environment (the general education classroom), thereby reducing wasteful interruptions to student programs.

As you think about this point, consider any "pullout" situations. Quite conservatively, the process of stopping an instructional activity in the general education classroom, "packing u'" to go to a special service, walking to that location, re-orienting to the instruction offered there, and then reversing all those steps upon returning to the general education classroom takes 15 minutes. Using this conservative estimate, students who leave the classroom one time each day for a special service are losing 75 instructional minutes each week just to get to their services.

In addition, the curriculum for a student in a pullout program often is fragmented. When general education and special services are separate, either a separate curriculum or lack of congruence in the curriculum and services is the common result. Even if general and special educators work collaboratively outside of class to plan an integrated curriculum, no matter how skilled the special educator, students often have difficulty generalizing what they have learned in a separate setting to activities in the general education setting. Thus, two types of program fragmentation may be reduced through coteaching: (a) temporal continuity of the student's learning opportunities; and (b) curricular continuity of the instruction and instructional process.

\section{Reducing the Stigma for Students}

A third part of a student-centered rationale for co-teaching concerns the stigma often associated with leaving the general education classroom to receive special education or related services (Redditt, 1991). The stigma derives from uninformed attitudes of students and teachers regarding special needs students' requirements for special education, related services, or remedial education. Although general education teachers and students may have little knowledge about what specific supplementary services entail, they associate negative attributes to them - and they often, however subtly, convey those perceptions to the special needs students. Some evidence suggests that students prefer to receive supports in classrooms with their peers rather than leave the classroom for special services (Walsh, 1992).
Although providing required supports for students in the general education classroom may be preferable to pulling them out for any number of reasons, a note of caution is warranted. The co-teaching framework to which we subscribe emphasizes that students with disabilities are taught the general education curriculum with needed modifications and support. They are included in instruction of the general education curriculum. We have seen many classrooms in which efforts to provide in-class services resulted in students with disabilities simply being pulled to the side to receive their instruction. In essence, these classrooms constitute a pullout model within the general education classroom and sometimes are referred to as "pull in" or "pull aside" approaches. The stigmatizing of students using this approach can be as great if not greater than in traditional special education pullout services, and few of the other benefits of co-teaching accrue to the student.

\section{Increasing Professional Support}

Another part of the rationale for co-teaching relates to the professionals and the extent to which they feel supported. For example, many co-teachers in elementary schools joke that the greatest benefit of co-teaching to them is that someone in the classroom gets their jokes! More seriously, co-teachers talk about the notions that they can relieve each other during instruction or help to clarify their partners' presentation, that they share the understanding that can only come from having been there for the best and worst moments of instruction, and that they can work together to more sensitively gauge student needs at any particular moment of instruction.

\section{WHEN IS CO-TEACHING THE APPROPRIATE INSTRUCTIONAL OPTION?}

Clearly, students' needs and skills and their match with the general education curriculum are the primary considerations when deciding if co-teaching is appropriate for a specific situation. The instructional strengths and needs of special needs students and typical students alike should be examined and deemed to be compatible and manageable by two teachers within a single classroom. In assessing the extent to which students will benefit from co-teaching, a number of factors arise that will assist in determining the appropriateness of coteaching. Several key questions are

- Is the content of the general education curriculum appropriate for the student?

- How much and what type of modifications and other support will the student require to benefit from the general education curriculum?

- Does the student require direct intervention or instruction that is entirely different from instruction other students receive?

- Is the ecology of the classroom appropriate for diverse learners?

- Do other students in this classroom need modified curriculum or instruction? 
These same questions provide a framework for making decisions about instructional design and modification. These topics are not discussed here but require serious consideration.

First, questions have to be asked about appropriateness of the general education curriculum for the student with a disability and the nature and intensity of support the student will need to benefit from participating in the general education instruction. Is the match between content and learning demands of the general education curriculum and the skills and learning needs of the student close enough to justify co-teaching? Although minor or major modifications in the level and amount of content, as well as modifications in the methods of instruction, probably will be required, the basic content of the general education curriculum should be determined to be appropriate for the student.

When a student requires direct intervention or instruction that is entirely different from what other students receive in the general education classroom, in-class delivery of the intervention most likely will not meet the definition of coteaching. The individualized decision-making process used to design the student's IEP should be followed to determine if these specialized services would be delivered most appropriately in the general education classroom or elsewhere (MacDonald \& York, 1991).

The next area of student needs to consider when deciding if co-teaching is a viable option focuses on the ecology of the specific class in which the student will participate and its appropriateness for the student. White and White (1992) have noted the importance of getting the right mix of students in one class. In doing so, we have to examine the learning needs of the students without disabilities and the composition of the group assigned to the potentially co-taught classroom. Is the ecology of the classroom likely to be conducive to co-teaching, to the inclusion of special needs students, and to the presence of a second teacher on a scheduled basis? For instance, is this class characterized by a wide range of diversity in teaching and learning styles? If the class already has several nondisabled students who might be at risk or who may have special learning needs, the addition of a limited number of students with disabilities probably will not alter the instructional demands of the overall classroom group significantly. At the same time, the accompanying addition of another teacher most likely will improve the quality of instruction, increase the intensity of instruction, and expand the instructional options for students.

Even though students might benefit from inclusion in general education classes and might be excellent candidates for co-teaching situations, a handful of classrooms and teachers will not be able to provide appropriate experiences for them. If a general education teacher is rigid or inflexible regarding student needs and classroom expectations or if the teacher treats students with little respect when they struggle to learn, many students assigned to that classroom likely will receive a poor education. This is a supervisory issue concerning professional performance and is a matter for administrative action. Attempting to use co-teaching as a remedy or substitute for a poor teacher would be a serious misuse of the approach.

\section{What Does Co-Teaching Look Like?}

One of the benefits of co-teaching is that the unique perspectives and strengths of general educators and special educators or other specialists are brought together to create teaching approaches and instructional strategies that could not occur if just one teacher were present (Friend, Reising, \& Cook, 1993). To accomplish this, co-teachers develop an array of classroom arrangements for their shared instruction. The following common co-teaching approaches, as outlined by Cook and Friend (1993), can serve as a starting point for considering how co-teaching might look in a classroom. They also are depicted schematically in Figure 1.

All the approaches have variations depending on the subject matter being taught, age and maturity of the students, and creativity of the teachers. No one approach is best or worst; each has a place in a co-taught class. In fact, each of the approaches - or some variation-is likely to be used alone or with another in any session of a co-taught class. They are presented here in what often proves to be a developmental order in terms of the amount of planning, trust, and comfort with one another that each requires of the teachers. Finally, all the approaches are presented as they would be used with instructional groups characterized by diverse student needs and including students with disabilities. Students with disabilities are dispersed among the instructional groups.

\section{One Teaching, One Assisting}

In this type of co-teaching, both educators are present, but one takes a clear lead in the classroom while the other observes students or drifts around the room, assisting them as needed. This approach is simple, limited teacher planning is required, and it provides the basic support to students that can make a class with diverse learning needs successful. It also has serious liabilities, though. When one teacher only observes or assists, especially if this role is assigned to the special educator, he or she may feel like a glorified teaching assistant. Students might question that teacher's authority in the classroom, too. These problems might be surmounted if the teachers alternate the lead and supportive roles.

As an example, consider the U. S. History class taught by Mr. Miles and the special education teacher Ms. Anderson. Although Mr. Miles takes the lead in much of the instruction because he has the content expertise in history, Ms. Anderson has a key role in the classroom. On Tuesdays she leads a current events activity while Mr. Miles assists in the classroom. 


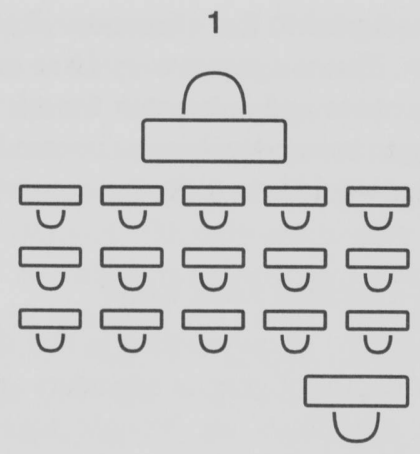

One Teacher, One Assistant

3

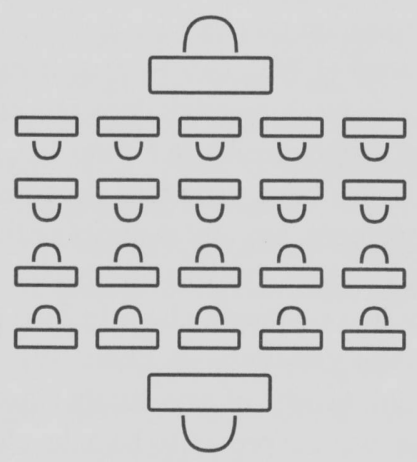

Parallel Teaching
2

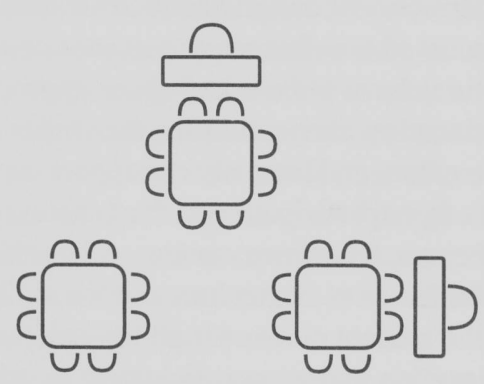

Station Teaching

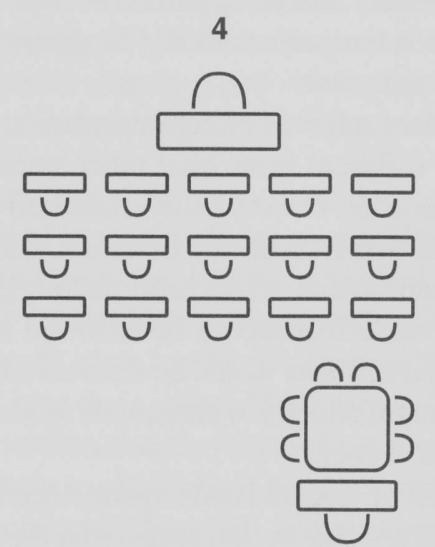

Alternative Teaching

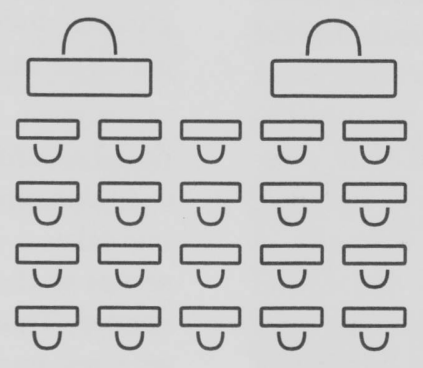

Team Teaching

Source: Adapted from Including Students with Special Needs: A Practical Guide for Classroom Teachers (p. 87), by M. Friend and W. Bursuck, 1996, Boston: Allyn \& Bacon.

\section{FIGURE 1}

Approaches to Co-Teaching

On Thursdays, during the last part of the class, Ms. Anderson leads students through a review of material covered and shows students how history affects contemporary society. The teachers planned these opportunities to add variety to the instruction for students and to make clear to students that Ms. Anderson is a "real" teacher.

\section{Station Teaching}

In station teaching, teachers divide instructional content into two, three, or more segments and present the content at separate locations within the classroom. With two teachers and two stations the teachers teach their half of the material and then trade student groups and repeat the same instruction. 
If students are able to work independently, a third station sometimes is created in which students work alone or with a partner on a related project or assignment. Although this approach requires that the teachers share responsibilities for planning sufficiently to divide the instructional content, each has separate responsibilities for delivering instruction.

This separating of instruction can increase the comfort level of inexperienced co-teachers. Students benefit from the lower teacher-pupil ratio, and students with disabilities can be integrated into all the groups instead of being singled out. Furthermore, equal teacher status in the classroom is not a serious concern because both teachers have active teaching roles. Potential drawbacks to station teaching include noise and a high activity level. Another challenge is that the teachers have to be able to pace their lessons well so the students are able to transition from one station to another at scheduled times. If one teacher extends the station time consistently while the second stays on schedule, conflict might arise.

Stations can be used at any grade level. In a first-grade classroom, students might spend 20 minutes at each of two math stations, one for introducing a new concept and one for practicing the concept taught last week. In an eighth-grade science class, students at one station complete an experiment while the other half of the class reviews for an upcoming test. In a high-school English class, students might go to a single station for an entire class period, rotating to new stations on subsequent days. One day students look at social and politi$\mathrm{cal}$ influences on society during a particular era. On another day, they read two examples of short stories from that era. On yet another day, they work with a learning partner to complete a short biographical sketch of a famous person from that time period. Station teaching has to be arranged so the order of material presented does not matter, but in many lessons this is not a serious issue.

\section{Parallel Teaching}

Parallel teaching also lowers the student-teacher ratio, so it often is used when students need opportunities to respond aloud, to engage in hands-on activities, or to interact with one another. In parallel teaching the teachers plan the instruction jointly, but each delivers it to a heterogeneous group consisting of half the class. For this approach to be successful, teachers have to coordinate their efforts so the students receive essentially the same instruction in approximately the same amount of time. This type of co-teaching lends itself to drill-and-practice activities, projects requiring close teacher supervision, and discussion of activities. As with station teaching approaches, noise and activity levels sometimes are problematic.

Teachers create a number of adaptations for this co-teaching approach. One of particular interest is using parallel teaching to teach students different perspectives on a topic, then having them share with one another. For example, in a unit on the environment, both groups receive instruction about endangered species, but one group is given the perspective of those who want to protect wildlife and the other learns about the economic problems that occur when wildlife protection leads to the loss of jobs. The students later discuss this issue together and use a problem-solving approach to address their differing points of view.

\section{Alternative Teaching}

Sometimes students with disabilities or other exceptional learning needs benefit from instruction in a smaller group than is customary in station or parallel teaching arrangements. In alternative teaching one teacher works with the small group (e.g., 3-8 students) while the other instructs the large group. For example, in a pre-teaching group students learn the vocabulary that will be introduced with tomorrow's lesson or pre-read the next short story or chapter. In re-teaching, already taught information is reviewed or taught using additional techniques or materials. Students who elect to have extra review or make up material missed during absences often ask to participate in reteaching groups. This approach also can be used to ensure that all students receive opportunities to interact with a teacher in a small group. Other uses of alternative teaching include providing an enrichment group, allowing an interest group to pursue a specific interest, and creating opportunities for an assessment group in order to check the development of student skills.

The greatest risk in this approach is stigmatizing students with disabilities by grouping them for re-teaching repeatedly, with or without other students included as group members. This risk can be avoided by varying groupings and ensuring that all students are periodically included in a group.

One interesting variation on this co-teaching approach is to use it for addressing a student's social skills. A student with need is targeted, and a small group of positive peer models is selected to join that student. The lesson taught is essentially the same as the one the large group is receiving, but an emphasis is placed on turn-taking, talking appropriately with others, or any other needed skill.

\section{Team Teaching}

In team teaching, both teachers share the instruction of students. The teachers might take turns leading a discussion, or one may speak while the other demonstrates a concept, or one might speak while the other models note taking on a projection system. The teachers who are teaming also role play and model appropriate ways to ask questions. This approach requires a high level of mutual trust and commitment. It is an approach with which some co-teachers might never be comfortable. On the other hand, many veteran co-teachers report that they find this type of co-teaching rewarding. They note that it gives them a renewed energy in their teaching and prompts them to try new ideas for reaching their students. 
Two teachers team taught an introductory lesson on debate using this approach. One of the teachers began the class and worked into the conversation her opinion that Tonya Harding's much publicized fall from favor was an example of media shaping public opinion in the absence of any concrete information. The other teacher jumped into the conversation by declaring that Nancy Kerrigan's career was nearly ended because of Harding's actions and that the press had nothing to do with the facts. Not surprisingly, within in a matter of minutes the teachers had the undivided attention of their class as the students anticipated how the teachers would solve their disagreement. After a short period of debate, the teachers transitioned into their lesson, using their own impromptu debate for examples to illustrate concepts.

Clearly, approaches to co-teaching should be selected on the basis of student characteristics and needs, teacher preferences, curricular demands, and pragmatics such as the amount of teaching space available. Most experienced co-teachers use many approaches, sometimes two or three even within a single lesson. They often also comment that one or two of the approaches just do not seem to fit their instructional setting. What is most crucial is to experiment with approaches, adapting them to fit specific situations to produce variety and appropriate use of teacher skills in the delivery of instruction.

\section{Who Should be Involved in Co-Teaching?}

The personal characteristics and the professional roles of the prospective co-teachers will influence the success of the co-teaching relationship and service. Consideration of these factors should precede decisions to co-teach.

\section{Co-teacher Characteristics}

Co-teaching is not a comfortable arrangement for all professionals. The issues of sharing responsibility, modifying teaching styles and preferences, and working closely with another adult represent serious challenges for some educators. Yet for others these same issues are a source of excitement that can lead to renewed enthusiasm about teaching. Thus, a first step for most co-teachers is to examine carefully their own readiness for the professional and personal demands of co-teaching, particularly the demands related to working closely with another professional. For example, co-teachers might use the following questions to reflect on their co-teaching readiness and to structure discussion among teaching partners. The discussion will help to initiate important communication between and among co-teachers.

1. To what extent am I willing to let someone else carry out teaching tasks at which I am particularly skilled?

2. How willing am I to allow a colleague to see aspects of my teaching in which I am not particularly skilled?

3. To what degree do I believe that there is more than one right way to carry out almost any teaching/learning task?
4. How willing am I to tell a colleague when I disagree about an issue or have a concern?

In addition to a general readiness to co-teach, several specific characteristics are associated consistently with successful co-teachers. Flexibility and commitment to the concept of co-teaching are considered essential (Armbruster \& Howe, 1985; Gelzheiser \& Meyers, 1990; Redditt, 1991). Strong interpersonal and communication skills, including collaborative problem-solving and decision-making skills, also are essential (Bauwens \& Hourcade, 1995; Pugach \& Johnson, 1995). Based on our work with co-teaching teams, we add strong clinical judgment as another essential characteristic for co-teachers. Co-teachers must have well developed judgment so they can evaluate the information they gain from colleagues and use it in their teaching and decision making.

Many writers, as well as the many teachers with whom we have worked, tell us that voluntariness on the part of the teachers is critical (Armbruster \& Howe, 1985; Dettmer, Dyck, \& Thurston, 1995) just as it is in all other forms of collaboration (Friend \& Cook, 1996). As in any close relationship, having skills and attitudes that foster collaboration and trust also is necessary. As many co-teachers report, "Co-teaching is like a marriage." We agree. It is a form of professional marriage.

\section{Professional Roles}

Although most new co-teaching programs emphasize general education and special education teachers sharing a classroom and some of our discussion here implies such arrangements, many different specialists can be involved in co-teaching. Indeed, the program planning and clinical literature includes numerous examples of successful co-teaching among vocational and special educators (Mori, 1979; Phelps \& Lutz, 1977), general educators and speech-language clinicians (Brush, 1987; Goodin \& Mehollin, 1990), and general educators and occupational therapists (Embers \& Robles, 1994). A key factor in determining if co-teaching is appropriate for related services professionals is the degree to which the students' related services needs can be met through modification of the general education curriculum. As examples, an occupational therapist might co-teach art, handwriting, or a hands-on vocational class, or a physical therapist might be present to co-teach an exercise or a game, while modifying as needed. As we noted earlier, decisions about these variations of co-teaching are to be made by an IEP team.

\section{How Much Co-Teaching Should Take Place?}

If you are considering co-teaching for the first time or thinking about improving your current co-teaching activities, you probably are entertaining the same questions that many professionals ask:

1. How can I physically co-teach in that many classrooms every day? 
2. What happens to the students on my caseload who require special curriculum and instruction apart from the general education classroom?

3. When and how am I going to have time to plan with my co-teachers?

4. How can I manage to co-teach and still keep up with the other responsibilities of my position?

Perhaps you will be encouraged to know that these questions, or some variation of them, are among those asked most frequently by school professionals as they embark upon coteaching. Our unqualified and definitive response to these questions is, "It depends!" Readers who are challenged positively by this response and its elaboration are likely to be the kinds of professionals who will consider and weigh the factors upon which co-teaching depends and use their ingenuity to develop the type of co-teaching program that will meet the needs of their students and the ecology of their schools.

Before considering the factors upon which co-teaching designs are built, readers should reflect on some of the notions presented in the previous section, namely, (a) not everyone is able to co-teach, and (b) successful co-teachers are flexible and use good clinical judgment. These two characteristics are important for a number of reasons, not the least of which is the responsibility that co-teachers have for problem solving and decision making as they collaboratively design programs and services to meet the individual needs of groups of students.

A large number of factors individually and collectively influence the amount of co-teaching that any one professional may do, just as they influence the number of students and classrooms that will be involved in the co-teaching program in a specific school. Several of the most salient factors are

- Size and grade levels of the schools

- Number of students with IEPs and their class/age distribution

- Number and disciplines of the specialists available to co-teach

- Level of administrative support

- Role responsibilities of potential co-teachers

- Stability of school enrollment and caseload composition

- Relevance of IEP to general education curriculum.

Clearly, the differences between large and small schools; among elementary, middle, and high schools; and among rural, suburban, and urban schools will influence the amount of co-teaching that can be offered. Related to these concerns is the number of specialists and whether they are available full time or part time as well as the range of available options for placing and scheduling students. Although these appear to be straightforward, they all interact to add complexity to the unique situations that typify individual schools.

Moreover, in most schools these factors are dynamic rather than stable. As one factor changes, it influences the others. For example, consider a school in an agricultural area where enrollments and, hence, caseloads fluctuate with seasons of the year because of the influx and outflow of migrant workers and their families. A program designed to meet student needs and school ecology during a season of low enrollment may be unable to expand to meet the needs of a large migrant population. If factors are considered in advance, they may be avoidable.

Ultimately the decision regarding the amount of co-teaching that is possible and desirable must be made at the local district and school levels. Strategies that veteran co-teachers have used successfully to increase their co-teaching opportunities include these:

1. Schools that have more than one special educator or related service provider assign special educators to serve students with IEPs who may not be on their caseloads.

2. The amount of specialized direct service the students require is reevaluated and the service is reduced when appropriate modifications can be made in the general education classroom.

3. Some students with IEPs are clustered in specific classes (or teams in secondary or year-round schools) without being seriously overrepresented in any class or program.

4. When writing the IEP, the general education context is examined and students' goals and objectives are written to be as compatible as possible with the core curriculum.

5. The schedules of students with disabilities are prepared before those of other students. This may require hand-scheduling in secondary schools, and it may create more structured schedules in elementary schools, but this option increases opportunities for serving students appropriately.

Potential co-teachers often fear that the first of these strategies will increase caseloads. This is not the intent. Rather, it is an approach to meeting identified student needs in general education classrooms without having a traffic jam with many different specialists darting in and out of the classrooms. For example, a speech-language specialist co-teaching with a sixth-grade teacher may provide instruction in organizing thoughts and ideas for written reports. If that also is an identified need for the two students with learning disabilities who are not on her caseload but are in that class, she may include them along with several unidentified students who need this instruction. The arrangement in this example ensures that the students with learning disabilities receive appropriate services from a qualified professional. It also frees some of the direct service time for the special education teacher who has these students on his caseload to co-teach in another classroom.

Each of these strategies could be discussed in depth. Our point is simply to raise a range of possibilities for consideration. Many co-teachers with whom we have worked have benefited from using the list as a stimulus for brainstorming alternative strategies that will be effective in their schools.

\section{How Can Co-Teachers Maintain a Collaborative Working Relationship?}

Successful co-teaching is more than planning lessons in which both educators are integral. It also relies on effective 
and ongoing communication. It is surprising how simple matters, if clarified, are easily resolved, but if not clarified sometimes lead to misunderstandings that interfere with co-teaching success (Redditt, 1991). For example, two teachers in an elementary classroom share the responsibility for leading the lesson. One, however, prefers that students who have to sharpen their pencils do it at any time, including during largegroup lessons, while the other wants students to remain in their seats and listen during large-group instruction. The first teacher's rationale is to take away from some students the game of asking to sharpen pencils. To the second, pencilsharpening is distracting and interferes with the instruction of all students. Neither is right or wrong, but they do need to discuss this matter before it becomes more than a source of annoyance for one or the other.

\section{Major Topics for Discussion}

The following are some of the topics that we discuss regularly with co-teachers to help them build and maintain positive working relationships. Questions that might be raised related to each are included in Table 1. Most co-teaching teams find that they have to add a few other topics to their discussion list and make a commitment to address them while they are still small matters rather than wait until they become major issues. We have found that using the topics as a discussion guide to be reviewed before beginning to co-teach and then periodically throughout the relationship helps to facilitate the open communication that is so essential to success in co-teaching.

\section{Instructional Beliefs}

Teachers' shared beliefs about teaching and learning are fundamental to successful co-teaching (Adams \& Cessna, 1991). If partners for co-teaching do not agree on their beliefs about the ability of all children to learn, the rights of children to experience success in their classroom, regardless their ability level, and their own role in student learning, they are likely to encounter difficulties when they share a classroom. Further, because teachers' instructional beliefs guide their practice, they also could find they do not agree on the general atmosphere that makes teaching and learning successful or the amount of activity and responsibility that students and teachers have during instruction.

\begin{tabular}{|c|c|}
\hline \multicolumn{2}{|r|}{$\begin{array}{l}\text { TABLE } 1 \\
\text { Questions for Creating a Collaborative Working Relationship in Co-Teaching }\end{array}$} \\
\hline Topic & Questions \\
\hline Instructional beliefs & $\begin{array}{l}\text { - What are our overriding philosophies about the roles of teachers and teaching, and students and } \\
\text { learning? } \\
\text { - How do our instructional beliefs affect our instructional practice? }\end{array}$ \\
\hline Planning & $\begin{array}{l}\text { - When do we have at least } 30 \text { minutes of shared planning time? } \\
\text { - How do we divide our responsibilities for planning and teaching? } \\
\text { - How much joint planning time do we need? } \\
\text { - What records can we keep to facilitate our planning? }\end{array}$ \\
\hline Parity signals & $\begin{array}{l}\text { - How will we convey to students and others (for example, teachers, parents) that we are equals in the } \\
\text { classroom? } \\
\text { - How can we ensure a sense of parity during instruction? }\end{array}$ \\
\hline Confidentiality & $\begin{array}{l}\text { - What information about our teaching do we want to share with others? } \\
\text { - Which information should not be shared? } \\
\text { - Which information about students can be shared with others? } \\
\text { - Which information should not be shared? }\end{array}$ \\
\hline Noise & -What noise level are we comfortable with in the classroom? \\
\hline Classroom routines & $\begin{array}{l}\text {-What are the instructional routines for the classroom? } \\
\text { - What are the organizational routines for the classroom? }\end{array}$ \\
\hline Discipline & $\begin{array}{l}\text { - What is acceptable and unacceptable student behavior? } \\
\text { - Who is to intervene at what point in students' behavior? } \\
\text { - What are the rewards and consequences used in the classroom? }\end{array}$ \\
\hline Feedback & $\begin{array}{l}\text { - What is the best way to give each other feedback? } \\
\text { - How will you ensure that both positive and negative issues are raised? }\end{array}$ \\
\hline Pet Peeves & $\begin{array}{l}\text { - What aspects of teaching and classroom life do each of us feel strongly about? } \\
\text { - How can we identify our pet peeves so as to avoid them? }\end{array}$ \\
\hline
\end{tabular}




\section{Planning}

A frequent concern of co-teachers is finding opportunities to plan. Even if time is limited, both teachers have to sense the direction the class is headed and how they play a role in it. Administrators need to recognize the importance of shared planning time and provide it for co-teachers (Cook \& Friend, 1993). Teachers committed to co-teaching often find unusual ways to create planning time. Some choose to meet before or after school, or to stay late one afternoon every other week. One clever teaching pair realized that they both liked to walk for exercise, so they brought walking shoes to school so they could exercise and plan at the same time.

A second part of planning concerns assigning responsibility for lesson planning tasks. Who will duplicate materials? Who will grade homework? There is no single, appropriate way to assign these types of responsibilities, and care must be taken not to overwhelm a special educator who might be coteaching in four or five different classrooms. Yet, if planning is not shared, the general education teacher often feels overburdened and the special educator feels as though he or she is not an integral part of the instruction.

\section{Parity Signals}

Earlier we mentioned that a goal in co-teaching is to have students respond to the teachers as classroom equals. To achieve and maintain this parity, teachers can arrange visual, verbal, and instructional signals that convey their equality. For example, teachers who co-teach daily can put both teachers' names on the board and on correspondence that goes to parents. They can arrange for two teachers' desks, or share a large work table instead of having one teacher camping at a student desk. They can be sure that both take the lead on delivering instruction, and they both can grade papers to make clear to students that both contribute to grades or other student evaluation. In new co-teaching programs in particular, listing all the ways that parity can be signaled sometimes is helpful.

\section{Confidentiality}

Co-teachers have to agree on which of their activities are to be public and which are to be confidential classroom matters. Even well intentioned co-teachers can inadvertently miscommunicate on this matter. For example, a special educator so enjoyed a teaching technique a general education teacher used that she shared it with several other teachers in the building, crediting the general education teacher from whom she had learned it. The teacher, however, took issue with the special educator's actions: She felt as though a teaching idea that was uniquely hers had been "stolen." Also, she thought the other teacher's actions put her in the awkward position of being singled out as an extraordinary teacher, something that violated the culture of the school. With a brief conversation, this and other issues about confidentiality could have been resolved.
Noise

Teachers have different levels of tolerance for the noise level of a classroom. Part of their working relationship requires taking into account the other person's preferences and reaching agreement on what is an acceptable noise level. Noise includes teacher as well as student voices, instructional activities (e.g., an experiment with humming equipment), and environmental sounds. The discussion also should include the signals that are used to quiet a class that is beyond acceptable noise limits.

\section{Classroom Routines}

As a matter of practicality, all classrooms, whether special education or general education, have routines. One type of routine is organizational. Organizational routines include the systematized ways in which the classroom is operated. Examples of organizational routines include how students prepare to leave a classroom, what they are to do when they enter class at the beginning of the day or class period, whether permission is given during instruction for students to leave the class, and so on.

The second type of routine is instructional. Instructional routines include the ways in which students are to organize their written assignments, including paper headings, lab and other report formats, and other conventions (for example, is work done in pencil or ink?). They also include ways students are to seek assistance, whether from another student or from the teacher, how they are to turn in assignments, and whether they are to keep assignment notebooks.

Sometimes teachers are surprised to learn how many routines operate in their classrooms. Both teachers, however, must know the routines, even if they tend to be those the general education teacher follows. At the very least, this shared knowledge prevents students from playing the teachers off against one another by seeing who will give them an answer they prefer.

\section{Discipline}

Many teachers have strong beliefs about acceptable classroom behavior. These beliefs are tied to the instructional beliefs mentioned already and can vary significantly among co-teachers. Co-teachers generally discuss what they expect of students in terms of behaviors, and the system of rewards and consequences used in the classroom. If some students in a co-taught class have behavior disorders, co-teachers typically discuss what the alternative expectations will be for those students so their message for them, as well as for other students, is clear.

\section{Feedback}

Co-teaching, especially when it is highly collaborative, includes providing feedback to one another on all aspects of the 
teaching and learning in the classroom. Co-teachers, however, might know and be able to tell their teaching partners the way they prefer to receive feedback. Some teachers want to know right away how their co-teacher viewed the lesson; others would prefer to gain the perspective of waiting a day. Some teachers prefer to discuss a positive lesson before discussing any problems that occurred; others prefer the reverse order. When we ask teachers with whom we work how to best give them feedback, a surprising number of them immediately say something like, "Bring chocolate!" Their irreverent comments might contain a grain of truth, especially if the feedback includes raising a concern or an issue.

\section{Pet Peeves}

Nearly every teacher has pet peeves about some aspect of teaching or the classroom environment that could interfere with a positive working relationship if it is not brought to the other teacher's attention. For example, some teachers are adamant that no one should open their desk drawers. Imagine their reaction if an unsuspecting teacher partner needs a pencil and heads for the desk. Other teachers are particular about how they want grades recorded or papers graded. Still others want teachers' manuals kept in a certain location or condition.

Other pet peeves relate to students. Students who rock on their chairs might be a pet peeve, or students who call their teachers "Teacher" instead of by name, or students who whine when they need to ask for help. The point is this: Part of co-teaching is respecting the other person's quirks as a teacher. Knowing your partner's pet peeves-as long as the list is relatively short-is one way to accomplish this.

\section{What Do Co-Teachers Need to Be Successful?}

A number of studies and reports identify what teachers and schools need to be successful whether they are offering traditional or more innovative services (e.g., Berman \& McLaughlin, 1978; Council for Exceptional Children, 1994; Research Triangle Institute, 1992). The two most critical needs that have not been addressed directly elsewhere in this paper are professional preparation and administrative support.

\section{Professional Preparation}

School professionals have been formally prepared and socialized to operate in isolation (Barth, 1990; Friend \& Cook, in press). To be successful in collaborative activities such as co-teaching, these professionals require opportunities for additional skill development in communication skills, instructional strategies, and collaborative planning. They will also need to acquire new knowledge and skills in program planning. Initial preparation should address the mutual needs of all involved. The preparation or training activities should focus on developing communication and collaboration skills, assessing one's readiness for collaboration and co-teaching, and designing the parameters of the co-teaching relationships. Instructional strategies and methods for joint delivery of instruction make up the instructional methods to be studied and developed. The special educators may need additional knowledge regarding specific curriculum areas. And the general educators may need to learn more about students with disabilities (Friend \& Cook, 1990). These specialized needs may be met through subsequent co-teaching experience.

The approach to professional preparation is particularly important. Ideally, readiness for co-teaching and other collaborative approaches will be promoted in preservice programs, which also should provide some initial experiences with collaborative planning and instruction. The most intensive professional development for co-teaching will occur when teachers and other specialists are in service and have opportunities to implement what they learn. Our experiences in providing both preservice and in-service education and our technical assistance experiences in co-teaching have demonstrated the necessity for preparation at both levels.

\section{Administrative Support}

Nearly every study of teacher performance and satisfaction finds that administrative support is essential to teachers' success (Berman \& McLaughlin, 1975). The research is less clear on the nature of the support teachers seek and the specific actions administrators can take to provide that support. Anecdotal and focus-group information suggests what administrative actions are needed to support co-teaching (Adams, Cessna, \& Friend, 1994; Cook \& Friend, 1993).

Administrators can support professional partners who coteach by modeling desirable traits that promote collaboration and by fostering those traits in others. Among the strategies that administrators have used successfully to support coteaching are (a) to help the co-teachers to plan and schedule their programs, (b) to provide incentives and resources that allow co-teachers to design and reflect about desirable changes in the way they provide services, and (c) to assist teachers in setting priorities that will protect their limited time. Committing resources to enhancing the preparation of co-teaching partners, participating with them in training activities, and scheduling additional planning time for co-teachers also are valued signs of administrative support.

\section{How Do We Plan for a Co-Teaching Program?}

Regardless of the extent of the co-teaching effort, some basic planning should precede implementation of a new program or service. Although successful co-teaching programs or other innovations can begin casually without systematic planning, these are rare. Planning not only is useful in preparing for implementation, but also is important in clarifying, for 
all involved, the specific expectations and changes that the program entails. This is discussed further in the later section on communicating with others. Planning allows everyone to start "on the same page" and identifies potential misunderstandings or problems in advance. Through these efforts, many future roadblocks can be avoided and facilitating conditions can be put into place.

Program planning and initiation are complex tasks that often are shortchanged because of time restrictions and other demands faced by the professionals involved. Planning of this sort is rather straightforward-perhaps so much so that it can be naively overlooked or considered unnecessary. Through our experiences with co-teaching, we have come to highly respect appropriate advance planning, particularly as it helps to reduce the frustration and stress resulting from badly planned change. Other sources that provide more detailed discussions of program planning include Adams and Cessna (1991), Friend and Cook (1990), and Reisberg and Wolf (1986). Here we provide an overview of the most basic steps in program planning.

\section{Establish a Planning Structure}

Whether it is for a large-scale, school-wide effort or just two professionals interested in providing more in-class services, the way in which planning will proceed will have to be decided jointly. Some schools establish a committee or task force of people who will be most involved. Other task forces have broader representation by including nonparticipating professionals, parents, and community members. In some cases the planning group may be small initially with co-teaching teams meeting together to design their own programs. We caution, however, that small planning teams may have logistical appeal but have less impact than larger groups that involve more stakeholders. If program expansion is planned, the participation of a larger group will become advisable.

\section{Describe the Program}

Co-teachers should agree on the general description of their co-teaching efforts. Mutually deciding what the program will be called (e.g., co-teaching, team teaching, teaching partners) often is helpful, along with a two- or three-sentence written description of the program. The description may be disseminated to others, but its greatest value probably derives from the sheer act of preparing it. When two or more individuals come together to commit to paper a description of what it is they are attempting to do, they discover points of confusion and ambiguity in their individual and mutual expectations. Identifying and resolving these points will be extremely beneficial in helping to ensure that their continued planning and their communication with others will be as clear and rational as possible.

\section{Specify Goals and Objectives}

Program goals and objectives will indicate the expected outcomes of the effort and provide a basis for subsequent evaluation. As with any changes designed and implemented in schools, new co-teaching programs often begin with general goals and objectives, which become defined more fully as the effort progresses. Goals and objectives are most realistic when they are developed with attention to factors including student needs, staff receptivity, and availability of time for general education teachers and special educators alike to interact and engage in joint planning. These and other factors will influence attainment of the desired outcomes.

\section{Determine Who is Eligible}

Once the desired program outcomes are specified, the next step is to decide who should receive services in a co-taught classroom. The issues raised earlier on deciding if co-teaching is an appropriate instructional option may assist in developing specific statements about eligibility. Asking the questions suggested in Table 1 relative to a specific population of students may help to clarify, in concrete ways, criteria for selecting students to participate. These criteria should be written and discussed thoroughly so eligibility for the program is clear.

\section{Specify Responsibilities}

Another planning task that is significant to participants as well as to interested others, is the specification of role responsibilities. Listing distinct responsibilities for all individuals affected by the co-teaching program will help everyone involved to understand the nature of the program and its potential impact for them. Obviously the co-teachers and any participating paraprofessionals will experience role changes, and their responsibilities will change. The responsibilities of others, such as administrators, other teachers or specialists, and multidisciplinary team members may change also. Resistance that may arise might reflect concerns about changing responsibilities. Providing adequate information can alleviate this resistance as well as provide a framework for continued planning.

\section{Outline the Types of Service}

Clarifying the nature of the services to be offered in a coteaching program is the final step. The earlier discussions about appropriateness of co-teaching and eligibility for service will assist in decisions regarding instructional services, but what of offering related services in a co-teaching format? The same considerations are likely to be useful here as well. The central consideration should be: Can the student receive appropriate related services while participating in the general education curriculum? For example, a student may be able to receive needed language development instruction by the speech therapist while participating in the general education social studies class. 


\section{Design Evaluation Strategies/Measures}

Evaluation is a vital component of any innovation in school-based services. Co-teaching is no exception. Both formative and summative evaluation are needed to develop and implement an effective co-teaching program adequately. Formative evaluation is needed to gather information that will signal the need to make modifications to goals, objectives, and strategies during initial implementation. This is the information that guides refinement and clarification of objectives and implementation strategies. Summative evaluation, conducted annually or more often, provides information that may lead to rethinking and revising the overall design of the co-teaching program. The summative evaluation is best conducted after the program has had an opportunity to have results. The evaluation should be designed to assess progress toward the desired outcomes specified in the program objectives.

Meaningful evaluation data have numerous sources. Quantitative measures of students' academic and social outcomes are extremely important to many stakeholders in evaluating co-teaching. Formal and informal measures of achievement, social relationships, and student behaviors also are useful. In some instances portfolio assessment is the most illuminating. Other extant data, such as attendance records, academic products, and discipline records, provide meaningful information regarding the program's effect on students. More qualitative sources also should be explored, as these often provide rich information that elaborates or clarifies the objective measures. Anecdotal information should be collected throughout the program, and various approaches for assessing perceptions of the students, parents, and professionals should be considered.

\section{How Do We Introduce Co-Teaching and Communicate with Others about It?}

Some schools invest considerable time in planning and preparing for co-teaching as a school-wide program. In other schools teachers enter into co-teaching in a much less systematic way. They see it as a good idea, agree on some initial principles, and "just do it." Regardless of the magnitude of the co-teaching effort and the amount of planning, the professionals involved are advised to communicate with others about their intent to offer services through co-teaching approaches. What information is shared and how it is communicated influence significantly how others view, and subsequently respond, to the co-teaching effort.

\section{Information to be Shared}

Stakeholders are bound to have questions and information needs that indicate specific levels of concern (Loucks-Horsley \& Hergert, 1985), and they need answers to these questions before they will be ready to accept a program change. Their questions reveal real concerns about the students' wel- fare and sometimes reflect a more generalized sense of resistance. We have been more successful in assuming that all questions stem from concern about student success rather than general resistance to change.

The stated concerns of the parents, administrators, students, teachers, and other adults will provide the framework for the information to be shared. The 10 planning questions presented in this article represent some of those asked most frequently as programs are introduced. Moreover, the planning steps described above (program description, goals and objectives, eligibility, responsibilities, types of services, and evaluation) yield the types of information that others will want to know about the program. If information from these two sources does not satisfy the stakeholder questions, it often is helpful to become an avid listener and promote discussion with the hope of identifying and alleviating unspoken concerns.

At least three areas of concern commonly arise and require consideration in advance.

1. The impact co-teaching may have on the nondisabled students. Will the nature of instruction and the standards for performance of all students be lowered to accommodate learners with special needs? Will nondisabled students receive less attention? At first blush lower standards and less instructional attention may seem to be consequences of co-teaching. Addressing these concerns is imperative.

2. The extent and purpose of co-teaching. Teachers, parents, paraprofessionals, related services professionals, and administrators all may fear that co-teaching will become the preferred approach to delivering services to students with special needs. Their concerns actually may reflect their fear of full inclusion, loss of services, loss or change in employment, significant role changes, and the like.

3. The need to schedule time for co-teaching and joint planning to prepare for co-teaching. This concern usually is restricted to the professionals in the schools because parents generally are unaware of the individual schedules of teachers and other school professionals. Scheduling services and planning time will be an important issue during program development and implementation.

The information presented previously should clarify what we intend co-teaching to mean and how we believe it should be used. These same questions and concerns will have to be addressed at local district and school levels. Experiences of implementers should be shared with interested parties to demonstrate solutions to the ever present challenges and to provide opportunities for others to help develop solutions.

\section{Approaches to Communication}

Various mechanisms are used for communication with individuals in varying roles in the educational community. Individuals who will be affected most by the program will have the greatest and most immediate need for information. The teachers and parents of the students in the co-taught classes, as well as the students themselves, may have the 
greatest interest in knowing about the program. Administrators also are on the front line in terms of information needs. The group with the next most pressing information needs will be individuals who may be affected by the program at a later date-teachers, specialists, parents, and students who are not participating currently but who may be expected to become involved sometime.

Schools have used several strategies to communicate about the development of new programs. When first planning a program, inviting key stakeholders to participate in the planning process is often helpful. Before implementing any changes, the parents of affected students should be informed through individual conferences, group meetings, or a letter sent to their homes. At the same time teachers and other specialists should be made aware of the change in service through an announcement at faculty or department meetings or through the established channels of communication at the school (e.g., faculty bulletins, electronic or other bulletin boards).

As the co-teaching effort matures, has evaluation or other data to support its expansion, and involves more professionals and students, more formalized mechanisms are appropriate. At this stage, letters or newsletters describing the project and any potential changes might be sent to all parents and other members of the school community. Depending upon the credibility of the data that support the project, schools also may choose to communicate with the broader community through news releases to a newspaper and to local organizations.

Regardless of which strategies seem to be most efficient, maintaining a balance of communication strategies is important. Too much reliance on one-way communication (e.g., from the school to the parents via written material) becomes ineffective because those who are informed do not have opportunities to question or clarify the information they receive. Equally troublesome, school professionals miss out on learning how parents respond to the information. People are more likely to accept and decide to participate in a new program or approach when they have been involved in its development at some level. Receiving and responding to information about the program being developed is one low-intensity activity that allows others to be involved in program development.

\section{SUMMARY}

Co-teaching is defined as two or more professionals delivering substantive instruction to a group of students with diverse learning needs. This approach increases instructional options, improves educational programs, reduces stigmatization for students, and provides support to the professionals involved. Co-teaching is an appropriate service delivery approach for students with disabilities who can benefit from general education curriculum if given appropriate supports. Teachers and related service professionals who are flexible and have good clinical judgment are likely to be successful in this role.

Various approaches to co-teaching include instructional support as well as station, parallel, alternative, and team teaching. The optimum amount of co-teaching in a school depends on a number of factors and must be determined by professionals at the site. Co-teachers need preparation, administrative support, and opportunities to nurture their collaborative relationships. Co-teaching programs should be planned and implemented systematically. Deliberate and ongoing communication among everyone involved is essential.

\section{REFERENCES}

Adams, L., \& Cessna, K. (1991). Designing systems to facilitate collaboration: Collective wisdom from Colorado. Preventing School Failure, 35(4), 37-42.

Armbruster, B., \& Howe, C. E. (1985). Educators team up to help students learn. NASSP Bulletin, 69(479), 82-86.

Barth, R. S. (1990). Improving schools from within. San Francisco: Jossey-Bass.

Bauer, H. (1975). The resource teacher-A teacher consultant. Academic Therapy, 10, 299-304.

Bauwens, J., \& Hourcade, J. J. (1995). Cooperative teaching: Rebuilding the school house for all students. Austin: Pro-Ed.

Bauwens, J., Hourcade, J. J., \& Friend, M. (1989). Cooperative teaching: A model for general and special education integration. Remedial \& Special Education, 10(2), 17-22.

Berman, P., \& McLaughlin, M. L. (1978). The analysis of verbal interactions occurring during consultation. Journal of School Psychology, 13, 209-226.

Brush, E. (1987). Public school language, speech and hearing services in the 1990s. Paper presented at annual convention of American Speech-Language-Hearing Association, New Orleans, November 1987. (ERIC Document Reproduction Service No. ED 295 383)

Choate, J. S. (1993). Co-assessment of special learners: A call for special and general education to unite. Preventing School Failure, 37, 11-15.

Cook, L., \& Friend, M. (1993). Co-Teach! Strategies for creating teaching teams. (In preparation).

Cook, L., \& Friend, M. (1993). Educational leadership for teacher collaboration. In B. Billingsley (Ed.), Program leadership for serving students with disabilities. Richmond, VA: State.

Dettmer, P. A., Dyck, N. T., \& Thurston, L. P. (1996). Consultation, collaboration, and teamwork for students with special needs (2d Ed.). Boston: Allyn \& Bacon.

Easterby-Smith, M., \& Olive, N. G. (1984). Team teaching: Making management education more student-centered? Management Education \& Development, 15, 221-236.

Embers, P., \& Robles, M. H. (1994). Occupational therapists in the classroom. Co-Teaching Network News, 2(3), 2.

Friend, M., \& Cook, L. (1990). Pragmatic issues in the development of special education consultation programs. Preventing School Failure, 35(1), 43-46. 
Friend, M., Reising, M., \& Cook, L. (1993). Co-teaching: An overview of the past, a glimpse at the present, and considerations for the future. Preventing School Failure, 37(3), 6-10.

Friend, M., \& Cook, L. (1996). Interactions: Collaboration skills for school professionals (2d Ed.). White Plains, NY: Longman.

Fuchs, D., \& Fuchs, L. S. (1992). Limitations of a feel-good approach to consultation. Journal of Educational and Psychological Consultation, 3, 93-98.

Garvar, A. G., \& Papania, A. (1982). Team teaching: It works for the student. Academic Therapy, 18(2), 191-196.

Gelzheiser, L. M., \& Meyers, J. (1990). Special and remedial education in the classroom: Theme and variations. Journal of Reading, Writing, and Learning Disabilities, 6, 419-436.

Goodin, G., \& Mehollin, K. (1990). Developing a collaborative speech-language intervention program in the schools. In W. A. Secord \& E. H. Wiig (Eds.), Best practices in school speechlanguage pathology. San Antonio, TX: Psychological Corp.

Graden, J. (1989). Redefining "prereferral" intervention as intervention assistance: Collaboration between general and special education. Exceptional Children, 56, 227-231.

Heron, T. E., \& Harris, K. C. (1993). The educational consultant: Helping professionals, parents, and mainstreamed students (3d ed.). Austin, TX: Pro-Ed.

Howell, P. (1991). Taking AIM to assist middle school students with special needs. Preventing School Failure, 35(4), 43-47.

Karge, B. D., McClure, M., \& Patton, P. L. (1995). The success of collaboration resource programs for students with disabilities in grades 6 through 8. Remedial and Special Education, 16(2), 79.

Little, J. W. (1982). Norms of collegiality and experimentation: Workplace conditions of school success. American Educational Research Journal, 19, 325-340.

Lortie, D. (1975). Schoolteacher: A sociological study. Chicago: University of Chicago Press.

Loucks-Horsley, S., \& Hergert, L. F. (1985). An action guide to school improvement. Andover, MA: ASCD The NETWORK.

MacDonald, C., \& York, J. (1991). Including students with disabilities in general education classes. What's working? Minneapolis: Minnesota Inclusive Education Technical Assistance Program.

MacIver, D. J. (1990). Meeting the needs of young adolescents: Advisory groups, interdisciplinary teacher teams, and school transition programs. Phi Delta Kappan, 71, 458-464.
Meyers, J., Gelzheiser, L. M., \& Yelich, G. (1991). Do pull-in programs foster teacher collaboration? Remedial \& Special Education, 12(2), 7-15.

Mori, A. A. (1979). Vocational education and special education: A new partnership in career education. Journal of Career Education, 6(1), 55-69.

Phelps, L. A., \& Lutz, R. J. (1977). Career exploration and preparation for the special needs learner. Boston: Allyn \& Bacon.

Phillips, V., \& McCullough, L. (1990). Consultation-based programming: Instituting the collaborative ethic in schools. Exceptional Children, 56, 291-304.

Pugach, M. C., \& Johnson, L. J. (1989). Prereferral interventions: Progress, problems, and challenges. Exceptional_Children, 56, 217-226.

Pugach, M. C., \& Johnson, L. J. (1995). Collaborative practitioners, collaborative schools. Denver: Love Publishing.

Redditt, S. (1991). Two teachers working as one. Equity \& Choice, $8(1), 49-56$.

Reeve, P. T., \& Hallahan, D. P. (1994). Practical questions about collaboration between general and special educators. Focus on Exceptional Children, 26(7), 1-11.

Reisberg, L., \& Wolf, R. (1986). Developing a consulting program in special education: Implementation and interventions. Focus on Exceptional Children, 19(3), 1-14.

Schulte, A. C., Osborne, S. S., \& McKinney, J. D. (1990). Academic outcomes for students with learning disabilities in consultation and resource programs. Exceptional Children, 57, 162-176.

Smith, S. C., \& Scott, J. L. (1990). The collaborative school. Eugene: University of Oregon, ERIC Clearinghouse on Educational Management.

Trump, J. L. (1966). Secondary education tomorrow: Four imperatives for improvement. NASSP Bulletin, 50(309), 87-95.

Walker, V. (1974). The efficacy of the resource room for educating retarded children. Exceptional Children, 40, 288-289.

Walsh, J. M. (1992). Student, teacher, and parent preference for less restrictive special education models-Cooperative teaching. Case In Point, 6(2), 1-12.

Warwick, D. (1971). Team teaching. London: University of London.

White, A. E., \& White, L. L. (1992). A collaborative model for students with mild disabilities in middle schools. Focus on Exceptional Children, 24(9), 1-10. 